\title{
The Role of Angiogenic Growth Factors in Arteriogenesis
}

\author{
Wilma Schierling ${ }^{a, b}$ Kerstin Troidl ${ }^{a} \quad$ Christian Troidl $^{a} \quad$ Thomas Schmitz-Rixen $^{c}$ \\ Wolfgang Schaper ${ }^{a}$ Inka K. Eitenmüller ${ }^{a}$ \\ ${ }^{a}$ Max Planck Institute for Heart and Lung Research, Bad Nauheim, bivision of Vascular and Endovascular Surgery, \\ University of Regensburg, Regensburg, and 'Division of Vascular and Endovascular Surgery, Goethe University, \\ Frankfurt am Main, Germany
}

\section{Key Words}

Arteriogenesis $\cdot$ Growth factors $\cdot$ Shear stress ·

Gene transfer $\cdot$ Hemodynamics $\cdot$ Receptors

\begin{abstract}
Background/Aims: Collateral vessels restore only about $40 \%$ of the maximum dilatory reserve after femoral artery occlusion, whereas complete normalization is reached by increased fluid shear stress (FSS). We studied the role of known potent angiogenic growth factors (separately or in combination) in arteriogenesis by determining their expression in FSS-stimulated collaterals and close-to-collateral infusion of growth factor peptides in a rabbit model of femoral artery occlusion. Methods: Values of maximum collateral conductance $\left(C_{\max }\right)$ and post mortem angiograms were compared to those achievable by high FSS. mRNA levels of growth factor ligands and receptors were determined in FSS-stimulated collaterals. Results: Seven days after vessel occlusion, FSS-stimulated legs showed a $C_{\max }$ not significantly different from that of not occluded femoral arteries. Arteriogenesis was significantly less enhanced after growth factor treatment (MCP-1 86\%, Ad5.1-FGF-4 75\%, bFGF 72\%, PDGF 64\%, VEGF $50 \%$ of $C_{\max }$ after FSS stimulation). RT-PCR showed no differential expression of FGF receptors, but an up-regulation of VEGF-receptor-2. Conclusion:The most potent known
\end{abstract}

angiogenic growth factors at high pharmacological doses reach only a fraction of the maximum conductance obtained by high FSS. Arteriogenesis differs from angiogenesis, so the main focus to markedly improve arteriogenesis should be put on the underlying mechanisms of shear stress.

Copyright $\odot 2009$ S. Karger AG, Basel

\section{Introduction}

Despite efforts to design new and efficient treatments for occlusive vascular diseases, they remain the most important cause for death and morbidity in industrialized societies. An important field of research concentrates on stimulating self-cure mechanisms [i.e., the growth of preexistent arterioles (collateral vessels) bypassing the obstruction], which is named arteriogenesis [1-3]. Although growing collateral arteries can potentially restore blood flow after coronary, cerebral or peripheral artery occlusions $[4,5]$, the adaptation remains incomplete in experimental (and most clinical) settings, even if arteriogenesis was stimulated by different growth factors or cyto-

Wilma Schierling and Kerstin Troidl contributed equally to this publication.

\section{KARGER \\ Fax +41613061234 E-Mail karger@karger.ch} www.karger.com
(C) 2009 S. Karger AG, Basel $1018-1172 / 09 / 0464-0365 \$ 26.00 / 0$

Accessible online at: www.karger.com/jvr
Prof. Wolfgang Schaper

Max Planck Institute for Heart and Lung Research

Parkstrasse 1, DE-61231 Bad Nauheim (Germany)

Tel. +49 6032705 409, Fax +496032 705458

E-Mail wolfgang.schaper@mpi-bn.mpg.de 
kines [5-9]. Angiogenesis and arteriogenesis differ in some important aspects; the most obvious difference is the dependence of angiogenesis on hypoxia and hypoxiainducible factor, which is crucial for angiogenesis, but not for arteriogenesis [10]. Collateral vessels never become hypoxic because they are always perfused by arterial blood and are embedded in normoxic tissue. Arteriogenesis depends on the proliferation of smooth-muscle cells following different principles than endothelial cells in angiogenesis. Furthermore, arteriogenesis is dependent on an inflammatory environment and invasion of monocytes [11], which play a role in angiogenesis only in special circumstances (wound healing), but not in hypoxic growth.

That exogenously applied angiogenic growth factors are active in arteriogenesis is not new, but the enhancements in blood flow recovery were either relatively small or the endpoints (i.e., normalization of normal maximum flow) were not defined. The relatively minor improvements of flow recovery under the influence of angiogenic growth factors could lead to the hypothesis that anatomical restrictions might make therapeutic strategies useless because of the increased length and tortuosity of collateral vessels, which increases their resistance. However, we have recently shown that imperfect adaptation by collaterals (only $40 \%$ of maximum dilatory reserve) can be surpassed by creating a situation of chronically increased fluid shear stress (FSS) [12]. A fistula between the distal stump of the occluded artery and the accompanying vein stimulated collateral growth to such an extent that normal maximal flow could be reached after only 1 week of elevated shear stress [12]. This means that no structural factors restrict the growth of collateral vessels and the new benchmark for therapeutic interventions is to reach normal maximal flow.

Using that new endpoint, we tested known potent angiogenic growth factors separately or in combination by external infusion of vascular endothelial growth factor (VEGF), basic fibroblast growth factor (bFGF), plateletderived growth factor (PDGF)-AB, monocyte chemoattractant protein (MCP)-1, MCP-1/bFGF, MCP-1/VEGF, $\mathrm{bFGF} / \mathrm{PDGF}-\mathrm{AB}$ and intra-collateral adenoviral gene transfer of FGF-4 and compared their activity with the level reached by increased FSS. In addition, we tested the transcriptional activity of these growth factors and their receptors by RT-PCR and genome-wide screening on microarrays to answer the question whether angiogenic growth factors and their receptors play a role in maximal growth stimulated collateral arteries obtained by high FSS.

\section{Materials and Methods}

Animal Models

The present study was performed with the permission of the government of Hesse, according to section 8 of the German law for the protection of animals. The investigation conforms to the Guide for the Care and Use of Laboratory Animals, published by the US National Institutes of Health (NIH publication No. 85-23, revised 1996).

Sixty male New Zealand white rabbits $(3.0 \pm 0.3 \mathrm{~kg}$ body weight; Charles River, Sulzfeld, Germany) were randomly assigned to 1 of 8 groups receiving a single growth factor, recombinant human FGF-4 adenoviral vector (Ad.FGF), albumin or control vector ( $\mathrm{n}=6$ each), or to 1 of 3 groups receiving growth factor combinations MCP-1/bFGF, MCP-1/VEGF, bFGF/PDGF ( $\mathrm{n}=3$ each). Surgical procedures were carried out under anesthesia with ketamine hydrochloride ( $40 \mathrm{mg} / \mathrm{kg}$ body weight) and xylazine $(4 \mathrm{mg} / \mathrm{kg})$ administered i.m. To prevent pain, buprenorphin (50 $\mu \mathrm{g} / \mathrm{kg}$ ) was applied.

For microarray analysis, 4 male Sprague-Dawley rats underwent arteriovenous shunt treatment as described below. Anesthesia was performed with ketamine hydrochloride $(100 \mathrm{mg} / \mathrm{kg}$ body weight) and xylazine ( $4 \mathrm{mg} / \mathrm{kg}$ body weight).

\section{Growth Factor Treatment}

Before treatment, we determined the maximum tolerable growth factor dose that did not cause toxicity (VEGF by scrotal edema, bFGF by hematological toxicity [13]). For MCP-1, high doses were already tested in previous studies [14].

After ligature of the femoral artery, 4 groups received single growth factor infusions, 3 groups received infusions of high pharmacological doses of growth factor combinations locally into the collateral circulation via osmotic minipumps for 1 week: MCP-1 (0.5 $\mu \mathrm{g} / \mathrm{kg} /$ day); VEGF-165 (6 $\mu \mathrm{g} / \mathrm{kg} /$ day); bFGF (3.5 $\mu \mathrm{g} / \mathrm{kg} / \mathrm{day})$; PDGF-AB (2 $\mu \mathrm{g} / \mathrm{kg} / \mathrm{day}) ;$ MCP-1/bFGF $(0.5 \mu \mathrm{g}+3.5 \mu \mathrm{g} / \mathrm{kg} / \mathrm{day})$; MCP-1/VEGF-165 (0.5 $\mu \mathrm{g}+6 \mu \mathrm{g} / \mathrm{kg} /$ day), and bFGF/PDGF-AB (3.5 $\mu \mathrm{g}+2 \mu \mathrm{g} / \mathrm{kg} / \mathrm{day}$ ) (all from Reprotech, Rocky Hill, N.J., USA). A control group received $1-\mathrm{mg} / \mathrm{ml}$ albumin in isotonic buffer.

\section{Intravascular Gene Transfer}

A temporary occlusion above and a ligature of the femoral artery below the feeding arteries of the collateral system were applied (fig. 1a). A plastic catheter was inserted into the femoral artery pointing upstream and $2 \mathrm{ml}$ of $0.9 \% \mathrm{NaCl}$ solution were infused to remove blood from the collateral arteries. Thereafter Ad.5.1FGF-4 (2.87 $\times 10^{10}$ PFU; Bayer-Schering, Leverkusen, Germany) was injected into the pre-existent collateral network. An adenoviral construct coding for green fluorescent protein (Ad.GFP; purified with Adenopack100; Sartorius, Göttingen, Germany) was used as a control. After $30 \mathrm{~min}$ of incubation, the temporal occlusions were removed and the femoral artery was permanently occluded.

\section{Arteriovenous Shunt}

Arteriovenous shunts (fig. 1b) were prepared as previously described $[12,15]$. Briefly, an arteriovenous fistula was created sideto-side between the distal stump of the occluded femoral artery and the accompanying vein to increase blood flow and thereby maintain FSS within the collateral arteries. 


\section{Hemodynamic Measurements}

Seven days after ligature of the femoral artery, rabbits were anesthetized again and in those with an arteriovenous shunt the fistula was closed. Maximum collateral conductance $\left(\mathrm{C}_{\max }\right)$ was quantified as described earlier [5]. In short, central blood pressure in the carotid artery, peripheral pressures in both saphenous arteries and blood flows in both iliac arteries were measured during maximum adenosine induced dilatation. $\mathrm{C}_{\max }$ was calculated using the following equation:

$$
\mathrm{C}_{\max }[\mathrm{ml} / \mathrm{min} / 100 \mathrm{~mm} \mathrm{Hg}]=\frac{\text { blood flow }[\mathrm{ml} / \mathrm{min}] \cdot 100}{\mathrm{CP}[\mathrm{mm} \mathrm{Hg}]-\mathrm{PP}[\mathrm{mm} \mathrm{Hg}]}
$$

where $\mathrm{CP}$ is the central pressure and $\mathrm{PP}$ is the peripheral pressure.

\section{Histological Analysis}

Histological analyses after transfection with Ad.GFP were performed. Hind limbs were perfused with physiological $\mathrm{NaCl}$ solution and afterwards with pFA (4\%). Both musculi quadriceps intermedius were harvested and cryopreserved. Tissues were cut into sections (6 $\mu \mathrm{m}$ thick). After postfixation with formaline (4\%), sections were washed in PBS and stained at $37^{\circ} \mathrm{C}$ with TRITC-BSI-Lectin (45 min; 1:30) followed by a nuclear staining with DAPI (10 min; 1:1,000). Pictures were taken with a Leica DC 200 microscope.

\section{Postmortem Angiograms and Isolation of Collateral Vessels}

To perform postmortem angiograms or to visualize collateral arteries intended to be isolated, hind limbs of euthanized rabbits were perfused with a gelatine- and barium-based contrast medium. Angiographically visible collateral arteries were counted according to the Longland classification [16].

\section{RNA Isolation}

PCR analyses were performed to verify the local restriction of adenoviral transduction of collateral arteries. Total RNA was isolated from different tissues of a rabbit 5 days after transduction with Ad5.1FGF-4 using RNeasy Minikit (Qiagen, Hilden, Germany). 300 ng of total RNA was transcribed using the superscript II system (Invitrogen, Karlsruhe, Germany). Human FGF-4 specific primers were used to amplify cDNA.

Changes in RNA expression of different collateral arteries after 7 days of increased FSS treatment (shunt) and ligature $(n=3)$ of different growth factor receptors, namely VEGFR (flk), FGFR1 IIIc, FGFR-2 IIIb, FGFR-2 IIIc, were investigated by RT-PCR (semiquantitative PCR).

\section{Microarray Analyses}

For microarray analysis, collateral arteries were harvested from rat hind limbs 5 days after arteriovenous shunt and sham surgery, as described above. RNA of collateral arteries was isolated after treatment with DNase-I (Turbo DNAfree; Applied Biosystems/Ambion, Darmstadt, Germany). RNA samples (arteriovenous shunt and sham) were linearly amplified for 2 cycles to average yields of $11 \mu \mathrm{g}$ cRNA (average 260/280 ratio 1.96) and subsequently labeled with Cy3- and Cy5 dyes (Amino Allyl MessageAmp ${ }^{\mathrm{TM}}$ aRNA Kit; Ambion) for microarray analysis. Each sample pair of arteriovenous shunt and control collaterals $(1 \mu \mathrm{g}$ cRNA per Cy-dye) was hybridized in duplicate, according to the

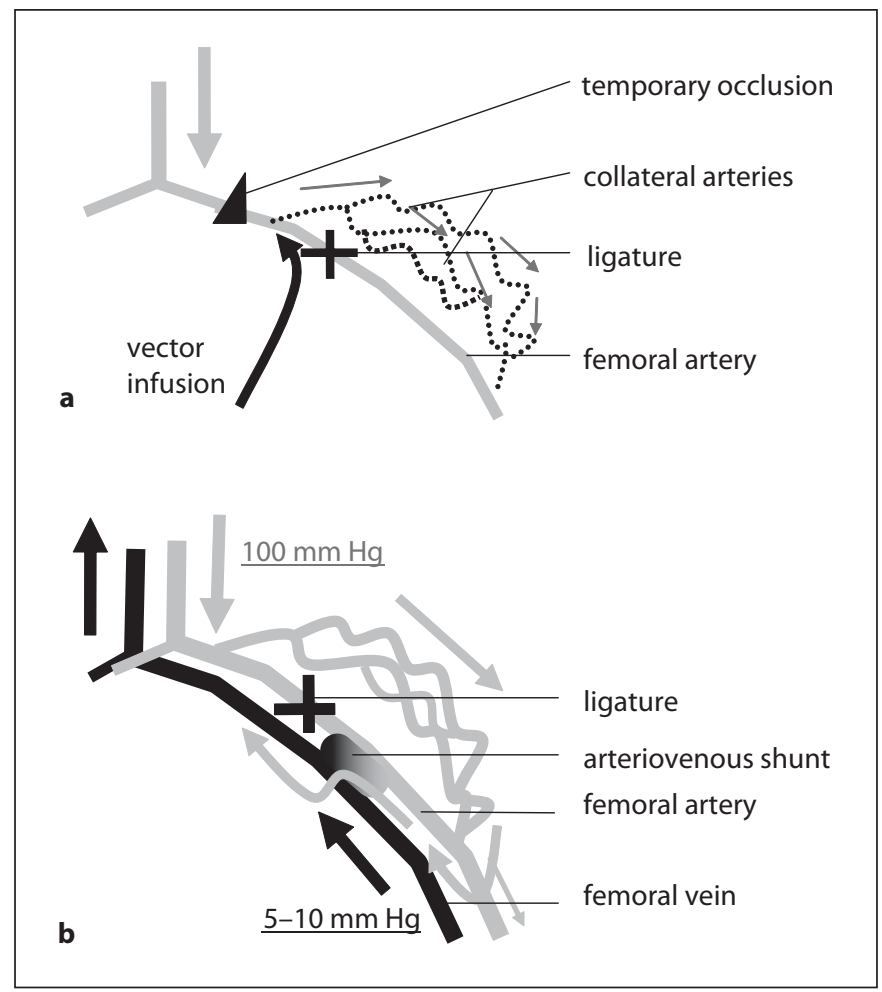

Fig. 1. a Intra-collateral gene transfer: the viral solution was infused into the segment of the femoral artery between the ligature and temporary occlusion. Via the feeding artery of the collateral system, the solution charged the collateral arteries and was incubated over a period of $30 \mathrm{~min}$. $\mathbf{b}$ Scheme of the shunt model showing surgical procedures and resulting changes in arterial and venous blood flow and pressure. Because of the direct connection to the vein, resistance in the femoral artery distal to the ligature falls, while blood flow and FSS within collateral arteries strongly increase. In turn, increased FSS leads to a strong stimulation of collateral artery growth.

dye-swap design, for $16 \mathrm{~h}$ at $40^{\circ} \mathrm{C}(25 \%$ de-ionized formamid, 20 mg yeast tRNA, Hyb buffer; Amersham). Microarray analysis was performed essentially as described [17].

\section{Statistical Analyses}

All values are expressed as mean \pm SEM. One-way ANOVA (Prism; GraphPad Software Inc., La Jolla, Calif., USA) was performed. $\mathrm{p}<0.05$ was considered statistically significant.

\section{Results}

Maximum Conductances after Growth Factor
Treatment Do Not Reach Shunt Level
In rabbits with control occluded femoral arteries,
max showed values of $133 \pm 12 \mathrm{ml} / \mathrm{min} / 100 \mathrm{~mm} \mathrm{Hg}$. Af-


Fig. 2. $C_{\max }$ (in $\mathrm{ml} / \mathrm{min} / 100 \mathrm{~mm} \mathrm{Hg}$ ) is shown after 1 week of treatment with different growth factors in comparison to controls and shunt treatment. The result after shunt treatment (increased fluid shear stress) is significantly higher compared to growth factor treatment. ${ }^{*} \mathrm{p}<$ 0.03 ; ${ }^{* *} \mathrm{p}<0.01$.

Fig. 3. Representative postmortem angiographies of variously treated rabbit hind limbs, 1 week after femoral artery ligature. Arrows show typical collateral arteries. a Control occluded femoral artery, few collaterals are visible. b After adenoviral gene transfer with FGF-4, collaterals are more numerous than in control angiographies. c Infusion of MCP-1 increased the collateral count. d Collateral arteries are multiplied and enlarged in diameter after shunt treatment.
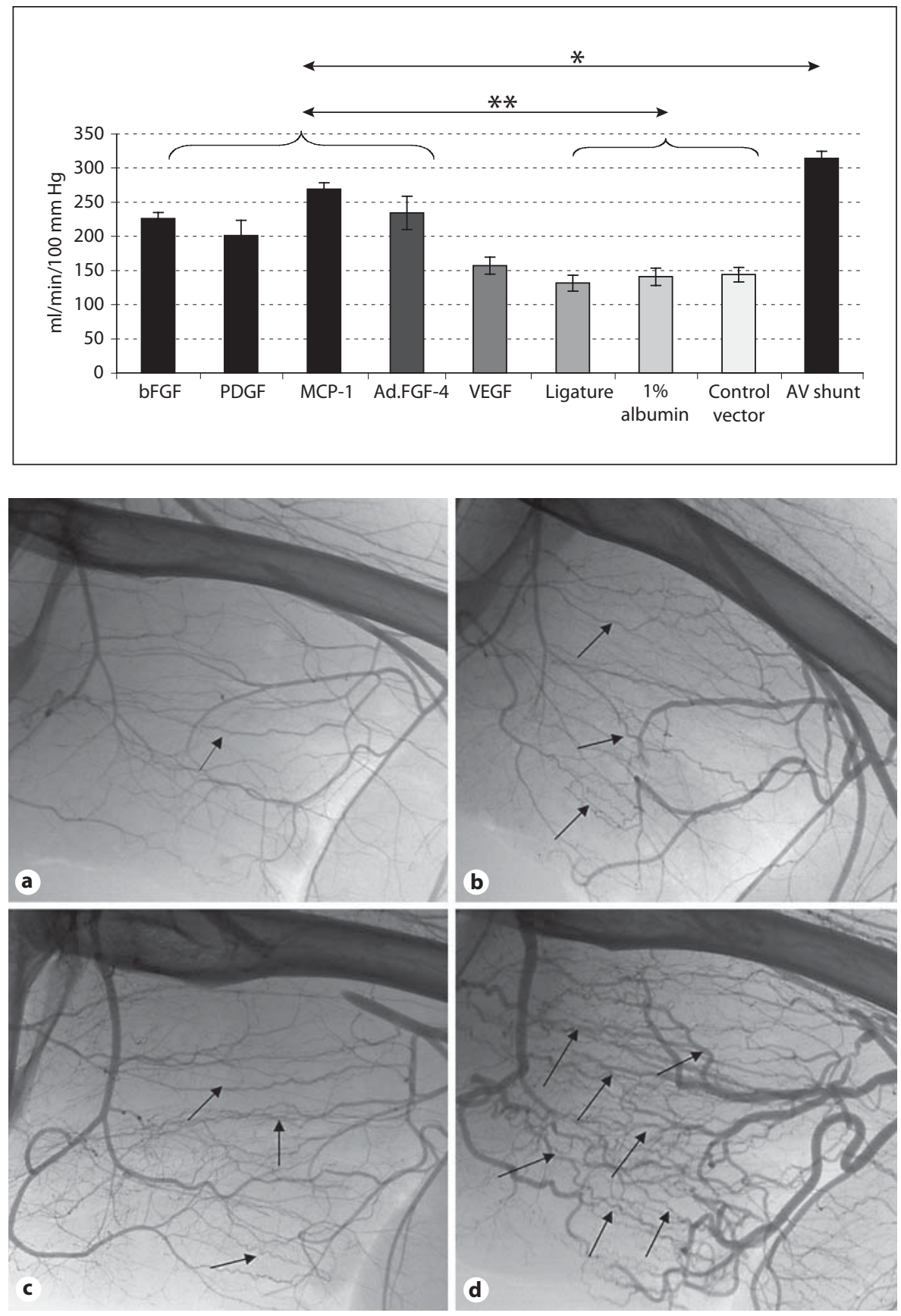

ter ligature of the femoral artery with additional shunt treatment to increase FSS, $C_{\max }$ was $312 \pm 10 \mathrm{ml} / \mathrm{min} / 100$ $\mathrm{mm} \mathrm{Hg}$. This result was significantly higher than that of the controls and closely approached the maximum conductance of unoccluded femoral arteries $(347 \pm 14 \mathrm{ml} /$ $\min / 100 \mathrm{~mm} \mathrm{Hg} ; \mathrm{p}=$ n.s.).

To compare the growth stimulating effect of high FSS with that of an established pro-arteriogenic factor, we in- fused MCP-1, which increased collateral blood flow to the highest observed rate in the growth factor group (269 $\pm 9 \mathrm{ml} / \mathrm{min} / 100 \mathrm{~mm} \mathrm{Hg}$ ), followed by bFGF (226 \pm $8 \mathrm{ml} / \mathrm{min} / 100 \mathrm{~mm} \mathrm{Hg})$, PDGF $(201 \pm 19 \mathrm{ml} / \mathrm{min} / 100$ $\mathrm{mm} \mathrm{Hg})$ and VEGF $(157 \pm 12 \mathrm{ml} / \mathrm{min} / 100 \mathrm{~mm} \mathrm{Hg})$, as shown in figure 2 . Although these values, with the exception of VEGF, differed significantly from control ( $1 \%$ albumin $140 \pm 12 \mathrm{ml} / \mathrm{min} / 100 \mathrm{~mm} \mathrm{Hg}$ ), they did not reach 
Fig. 4. Diagram shows collateral artery count for different groups. Collateral count after growth factor treatment is significantly higher compared to control treatments, but significantly lower compared to shunt treatment. ${ }^{*} \mathrm{p}<0.01$.

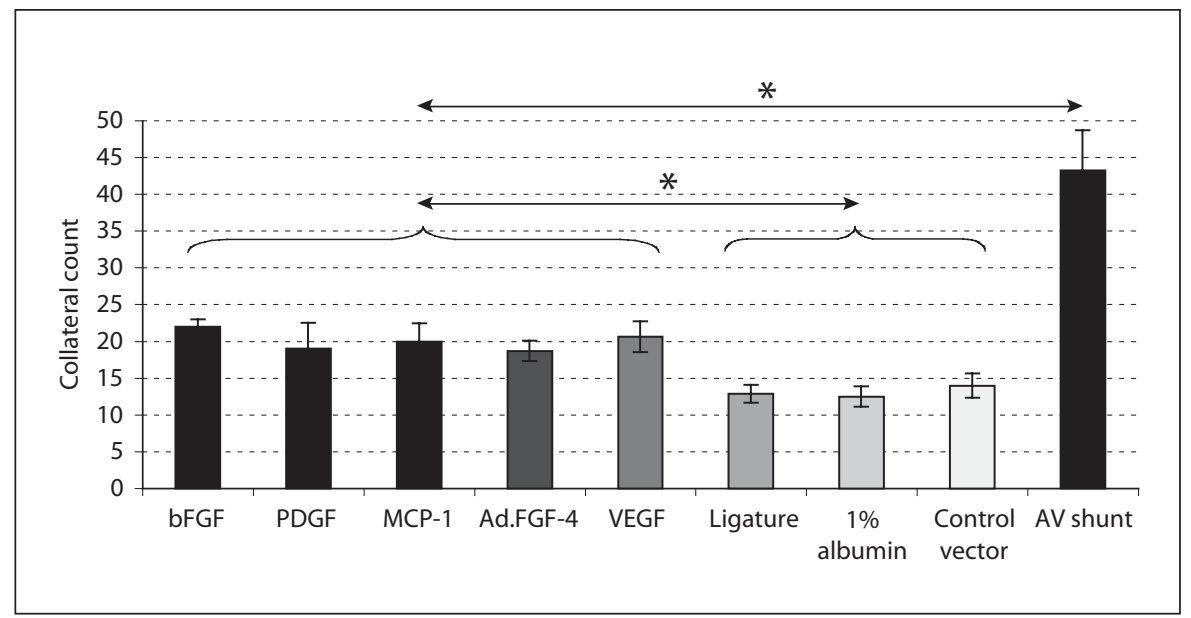

the level of shunt-treated ligatures $(\mathrm{p}<0.03) . \mathrm{C}_{\max }$ can be expressed as a percent of shunt values: MCP-1 86\%, bFGF $72 \%$, PDGF $64 \%$ and VEGF $50 \%$. None of the tested growth factor combinations of MCP-1/bFGF, MCP-1/ VEGF or bFGF/PDGF led to additional effects compared to single MCP-1 or bFGF infusion (data not shown).

After intracollateral gene transfer of Ad5.1FGF-4, $\mathrm{C}_{\max }$ was $234 \pm 24 \mathrm{ml} / \mathrm{min} / 100 \mathrm{~mm} \mathrm{Hg}$ (vs. control transduction $144 \pm 10 \mathrm{ml} / \mathrm{min} / 100 \mathrm{~mm} \mathrm{Hg}, \mathrm{p}<0.01$ ), which was $75 \%$ of conductance after shunt treatment $(\mathrm{p}<0.03)$.

\section{Collateral Count after Shunt Treatment Had Doubled} Compared to Growth Factor Treatment

To further correlate hemodynamic results with morphometric parameters, numbers of visible collateral arteries in the different groups were counted (fig. 3). Compared to control groups (albumin $12 \pm 1$ and control vector $14 \pm 1)$, collateral numbers in MCP-1 $(20 \pm 1)$, bFGF (22 \pm 1), VEGF (20 \pm 2$)$, PDGF (19 \pm 3$)$, and Ad5.1FGF$4(18 \pm 1)$ were significantly increased. Compared to shunt-treatment (43 \pm 5$)$, collateral counts after growth factor therapy were significantly lower ( $\mathrm{p}<0.01$; fig. 4).

\section{Adenoviral Gene Transduction Is Locally Restricted to} the Site of Transduction

A transgene-specific PCR of human FGF-4 revealed a locally restricted transduction of Ad5.1FGF- 4 in collateral arteries of the virus-treated hind limb. An accumulation of excessive virus was detected in the spleen and, to a lesser extent, in the liver (fig. 5c).

Histological results after transduction of Ad.GFP aligned with RT-PCR analysis, green fluorescence was only found in collateral arteries of transduced hind limbs (fig. 5a, b).

\section{Most Growth Factor Receptors Are Not Up-Regulated after Increased FSS}

Microarray analyses showed that angiogenic factors (PDGF, FGF-2, FGF-4) and their receptors were not upregulated after 5 days of increased FSS.

Semiquantitative RT-PCR analyses of control-occluded collateral arteries or after 7 days of increased FSS were performed in order to detect a potential differential abundance of selected growth factor receptor transcripts. The content of mRNA of FGFR-1 IIIc and FGFR-2 IIIb was not increased in FSS-stimulated collateral arteries, and mRNA of FGFR-2 IIIc could not be detected (fig. 6). mRNA of flk-1 (VEGFR-2) was up-regulated after 7 days of increased FSS.

\section{Discussion}

Independent of localization in the various organs (coronary, cerebral, renal or peripheral), collateral vessels are easily identifiable by their tortuous course. Tortuosity means also an increase in length, and both add to the hemodynamic resistance and cause energy loss. Resistance in curvature flow is difficult to predict, but follows in principle the Dean equation, which means that tight turns of the vessels increase the Dean number and resistance $[18,19]$. Since the development of collateral vessels after arterial occlusion stops prematurely and reaches only about $40 \%$ of the functional capacity of the artery before occlusion, it was assumed that compensation by 
Fig. 5. Verification of single-sided local gene transfer (a, b). Histological investigations of collateral arteries after single-sided intracollateral transfection with Ad.GFP. a Collateral artery of the not transfected leg. Magnification $\times 40$. $\mathbf{b}$ Collateral arteries of the transfected leg. The green color indicates presence of GFP. Magnification $\times 40$. c Results after PCR of human FGF-4 in different tissues after single-sided transfection with Ad5.1FGF-4. Only collateral arteries of the transduced leg (3), spleen (11) and liver (12) showed PCR products.
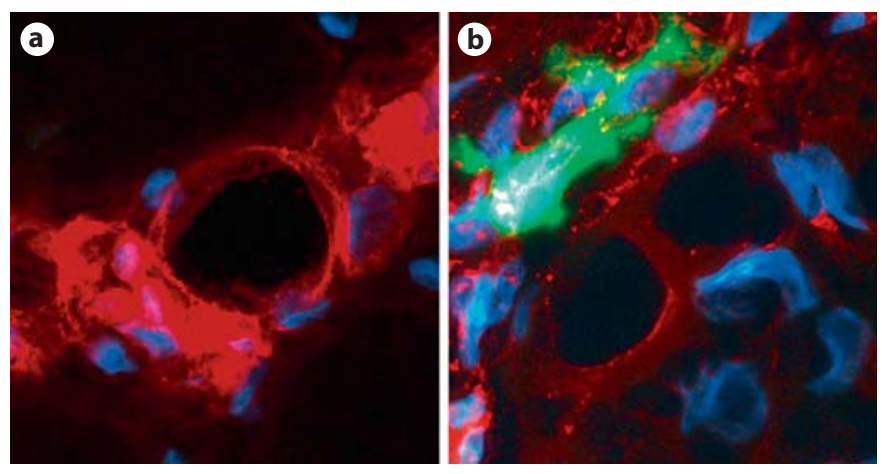

C

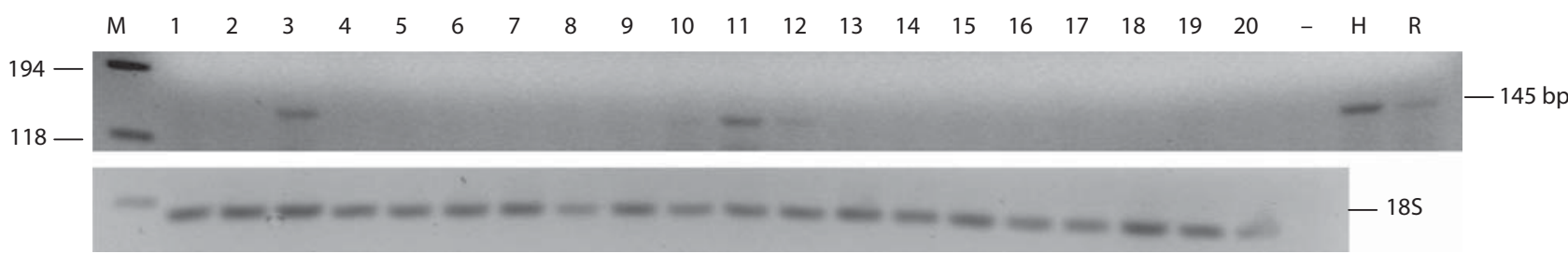

M Size marker

1 A. profunda femoris, transduced leg

11 Spleen

12 Liver

13 Heart

3 Collateral artery, transduced leg

4 Collateral artery, control leg

5 A. saphena, control leg

6 A. saphena, transduced leg

7 A. femoralis, control leg

8 A. femoralis, transduced leg

9 A. iliaca, control leg

10 A. iliaca, transduced leg

\section{Brain}

15 Testes, transduced side

16 Testes, control side

$17 \mathrm{M}$. vastus intermedius, transduced leg

$18 \mathrm{M}$. vastus intermedius, control leg

19 M. gastrocnemius, transduced leg

20 M. gastrocnemius, control leg collaterals is a self-limiting process that is resistant to stimulation. In a recent study, we could show that the cause for the premature halt in collateral development is not anatomical constraint, but rather the premature fall in FSS, which is related to the cube root of the expanding radius [12]. When the FSS is prevented from becoming normalized by the growth process through creation of a fistula between the peripheral stump of the occluded artery and the accompanying vein, draining most of the collateral flow into the venous system, complete normalization of the full vasodilatory reserve could be achieved [12].

Without anatomical constraint, growth factors should be able to significantly improve the function of collateral vessels after femoral artery occlusion. In the present study, we investigated the question of whether angiogenic growth factors are able to mimic the effects of high shear stress when exogenously applied and whether they and their cognate receptors are involved in FSS-stimulated collateral artery growth. Growth factor studies have shown that those stimulating angiogenesis are also able, after exogenous application, to stimulate arteriogenesis. However, it remained unclear what the endpoints of these studies were and how close the effect was to the physiological situation. In the present study, we show that complete normalization can be reached, but that angiogenic growth factors in high pharmacological doses do not achieve the same level as FSS does.

In various studies, it was shown that growth factors and cytokines, at least under experimental conditions, are potent stimulators of arteriogenesis, capable of reducing signs of critical ischemia and improving collateral conductance $[4,5,11,20-22]$. Although most of these studies showed differences compared to untreated controls, the 
degree of compensation with regard to the maximum was not known because no maximal endpoint could be defined until now. A few studies [23] compared the effects of treatment with the maximum normal flow under vasodilatation, but it remained unknown whether the growth factor treatment was reaching the maximum achievable level.

Nevertheless, even under experimental settings it could not be shown at any time that the collateral circulation was able to completely compensate for the occluded artery after growth factor treatment, whereas we could show that increased FSS is able to rapidly stimulate arteriogenesis. In our experiment, FSS was enhanced and maintained within the collateral circulation by a surgical intervention, an arteriovenous shunt, connecting the femoral artery to the femoral vein $[12,15]$. Because of the direct connection to the venous system, a pressure gradient along pre-existing collateral vessels was generated. The decreased resistance induced a strong and sustained increase in blood flow, and hence FSS, in the collateral arteries. Although the complete molecular mechanisms of the growth-regulating effect of increased FSS on collateral arteries are not known, it was shown that FSS activates the Ras-ERK and Rho pathways [12]. Despite the fact that the Ras-ERK pathway is strongly involved in the transmission of growth factor-initiated signals to cell proliferation [24], none of the angiogenic growth factors applied in this study is capable of matching the effect of increased FSS on arteriogenesis.

\section{Gene Transfer Studies}

Gene transduction of vascular smooth-muscle cells in vivo remains a problem, although different catheters and methods are available for vascular transfection $[25,26]$. Nevertheless, none of these methods are suitable for the transduction of pre-existing collateral arteries because of their small dimensions. As well as the size of the collateral arteries, which leads to the problem of local delivery, barrier properties of the vascular wall also reduce the transduction efficiency of adenoviral vectors for vascular tissue $[27,28]$.

In some studies, intramuscular transfection was used to stimulate arteriogenesis [29-31]. However, although collateral artery growth can be enhanced, this method is not able to specifically target collateral arteries. It is still unclear whether transfection of surrounding skeletal muscle cells may influence the remodeling process within the collateral vessel wall. Therefore, a new specific method of intracollateral gene transfer was required to analyze the potency of adenoviral vectors in enhancing collateral growth.

Growth Factors in Arteriogenesis

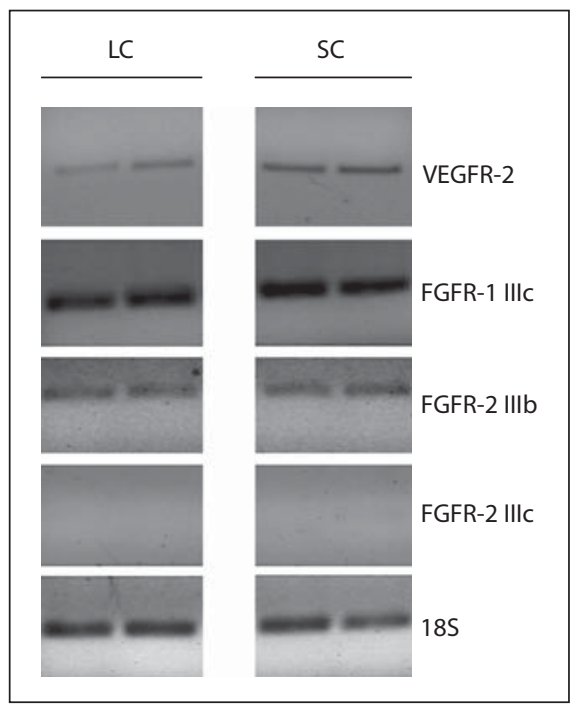

Fig. 6. Semiquantitative analyses of mRNA expression of growth factor receptors in ligature collaterals (LC) and shunt collaterals (SC). FGFR-IIIc was not detected. FGFR-1 IIIc and FGFR-IIIb showed no differential expression, whereas an up-regulation of VEGFR-2 could be shown.

We developed a model which assures that the applied virus can sufficiently interact with the collateral wall cells, hence increasing transduction efficiency $[27,32]$.

PCR analyses after intracollateral transduction revealed human FGF-4 transcripts only in collateral arteries of the transduced leg, in the spleen and, to a lesser extent, in the liver. This indicated a high specificity of this gene transfer technique because over-expression is restricted to transduced collateral arteries, which was confirmed by histology.

Other arteries did not show FGF-4 transcripts. The fact that we did not find endogenous rabbit mRNA of FGF-4 may be due to the observation that FGF-4 expression is restricted to embryogenesis and some types of cancer [33].

\section{The Role of Angiogenic Growth Factors in \\ Arteriogenesis}

The differences between growth factor- and FSS-stimulated arteriogenesis caused us to investigate the expression of growth factor receptors in strongly growing FSSstimulated collateral arteries to test the hypothesis that growth factor-stimulated arteriogenesis is limited by the availability of growth factor receptors. We performed PCR analyses for rabbit gene sequences of FGFR-1 III, FGFR-2 IIIb and FGFR-2 IIIc and VEGFR-2 in FSS-stim- 
ulated collateral arteries. The rabbit gene sequence for PDGFR is presently not available. It is known that FGFR1 is upregulated and activated in the early phases of arteriogenesis $[34,35]$. Even though arteriogenesis is not selflimiting in our shunt model, expression of FGF-receptors is not upregulated under conditions of elevated FSS. Our observation that VEGFR-2 is up-regulated in FSS stimulated collaterals is consistent with other studies demonstrating that VEGFR-2, together with PECAM-1 and VEcadherin, is part of a mechanosensory complex, and that 2 methods of VEGFR-2 activation exist: ligand-dependent and ligand-independent activation by FSS as a mechanotransducer for eNOS activity [35-37]. Additionally, we and others showed that inhibition of NO-synthesis blocked the effect of increased FSS $[12,38]$.

In our hemodynamic measurements, we confirmed that VEGF does not belong to the most powerful growth factors stimulating arteriogenesis [5]. However, external application of VEGF increased markedly the collateral count, as shown in postmortem angiograms. The discrepancy between functional and morphological results reflects earlier reports that VEGF induces growth of immature vessels with inferior blood conducting function [39].

For application, we used continuous intravascular infusion of high pharmacological doses of angiogenic growth factors or adenoviral gene transduction. Local intra-arterial delivery has proven to be superior to all other models of administration (e.g. intravenous, intramuscular, intrapericardial) because it allows prolonged exposure of the vasculature itself to therapeutic growth factors [40]. Hemodynamic measurements and collateral counts showed that all growth factors markedly promoted the growth of collateral arteries, though none of them reached the maximum conductance of nonoccluded femoral arteries, as shunt treatment did. The strongest recovery was achieved by MCP-1 followed by FGF. These factors activate and stimulate adhesion of monocytes and macrophages which are known to play an important role in collateral growth, partly also as producers of FGF-1 and FGF-2 [7, 14, 34, 40-42].

We further tested the hypothesis that growth factor combinations are needed to improve results. Surprisingly, no growth factor combination used in this study led to additional effects compared to single factor application. This is not in contradiction to other studies because growth factors separately or in combination are very potent in stimulating arteriogenesis in combination with angiogenesis in ischemic hind limb models [43-46], but they were never able to completely restore the conductance capacity of a larger artery. Alternatively, we used a hind limb model where the region of collateral growth is not ischemic. For stimulating arteriogenesis by itself, known endogenous growth factors do not play the leading part, as shown in this study. We cannot exclude that there might be other combinations that are more efficient. However, their efficiency was shown only for angiogenesis.

Our previous studies with different methods of gene expression including genome-wide profiling with microarrays showed no increased transcription of the mentioned angiogenic growth factors (VEGFA, FGF-1, FGF2 , PDGF) or their receptors in growing collaterals, with the exception of MCP-1. On the other hand, there is evidence that growth-promoting factors, especially FGFs, are supplied by monocytes in a paracrine manner [34]. It is therefore not surprising that high pharmacological doses of growth factors are able to mimic parts of the natural process of arteriogenesis in an indirect way.

Nevertheless, chronic elevation of FSS by the shunt model is the only force that can completely restore (and overshoot) the physiological function of an occluded femoral artery. In shunt-treated animals, collateral count doubled compared to growth factor treatment and maximum conductances reached values of nonoccluded arteries at day 7 , increasing further to double compared to nonoccluded arteries at 4 weeks [12]. The reason for the apparent discrepancy between the shunt effect on the collateral score (doubling compared to growth factor treatment) and on maximum conductance (e.g. MCP-1 reached $86 \%$ of shunt values) at day 7 is the higher degree of tortuosity of collaterals after shunt treatment, leading to a higher Dean number and resistance $[18,19]$. However, tortuosity is not a limiting factor for the development of collaterals [12].

To our knowledge, this is the first study comparing the influences of shear stress with that of growth factor application on restoration of dilatory reserve capacity in a direct manner. There are some limitations to this study. With all growth factors, we used the maximum tolerable dose and did not test if submaximal doses or other application modalities had any different effects. To quantify arteriogenesis, we measured collateral conductance during maximum adenosine-driven vasodilatation, as exercise-induced vasodilatation is not feasible in rabbits. Of course, shunt treatment is not applicable in patients. But against the background of the negative outcome of clinical growth factor trials [40], it appears worthwhile to unravel the molecular events that occur with high shear stress to markedly improve the situation of patients with occlusive vascular diseases.

We conclude that increased FSS has the strongest stimulating effect on arteriogenesis because collateral ar- 
teries can completely restore the maximum normal conductance within 1 week after femoral artery ligature, when FSS is sufficiently elevated. In contrast to this, growth factors applied at high pharmacological doses reach only a fraction of the maximum.

This highlights the fact that angiogenesis and arteriogenesis are differently regulated processes. Our studies with increased FSS define an endpoint for further studies employing new growth factors or pharmacological agents.

\section{Acknowledgments}

The authors would like to thank Sandra Ruehl for her expert technical assistance. This study was funded by grants from the German Society for Cardiac Research, the German Cardiac Society, the Kuehl Foundation and the William G. Kerckhoff foundation.

\section{References}

1 Heil M, Eitenmuller I, Schmitz-Rixen T, Schaper W: Arteriogenesis versus angiogenesis: similarities and differences. J Cell Mol Med 2006;10:45-55.

2 Scholz D, Cai WJ, Schaper W: Arteriogenesis, a new concept of vascular adaptation in occlusive disease. Angiogenesis 2001;4:247257.

3 Helisch A, Schaper W: Arteriogenesis: the development and growth of collateral arteries. Microcirculation 2003;10:83-97.

-4 Unger EF, Banai S, Shou M, Lazarous DF, Jaklitsch MT, Scheinowitz M, Correa R, Klingbeil C, Epstein SE: Basic fibroblast growth factor enhances myocardial collateral flow in a canine model. Am J Physiol 1994;266:H1588-H1595.

5 Pipp F, Heil M, Issbrucker K, Ziegelhoeffer T, Martin S, van den Heuvel J, Weich H, Fernandez B, Golomb G, Carmeliet P, Schaper W, Clauss M: Vegfr-1-selective VEGF homologue PLGF is arteriogenic: evidence for a monocyte-mediated mechanism. Circ Res 2003;92:378-385

-6 Fujii T, Yonemitsu Y, Onimaru M, Tanii M, Nakano T, Egashira K, Takehara T, Inoue M, Hasegawa M, Kuwano H, Sueishi K: Nonendothelial mesenchymal cell-derived MCP-1 is required for FGF-2-mediated therapeutic neovascularization: critical role of the inflammatory/arteriogenic pathway. Arterioscler Thromb Vasc Biol 2006;26:2483-2489.

$\checkmark 7$ Ito WD, Arras M, Winkler B, Scholz D, Schaper J, Schaper W: Monocyte chemotactic protein-1 increases collateral and peripheral conductance after femoral artery occlusion. Circ Res 1997:80:829-837.

-8 Buschmann IR, Hoefer IE, van Royen N, Katzer E, Braun-Dulleaus R, Heil M, Kostin S, Bode C, Schaper W: GM-CSF: a strong arteriogenic factor acting by amplification of monocyte function. Atherosclerosis 2001; 159:343-356.
Lebherz C, von Degenfeld G, Karl A, Pfosser A, Raake P, Pachmayr F, Scholz D, Kupatt C, Boekstegers $P$ : Therapeutic angiogenesis/arteriogenesis in the chronic ischemic rabbit hindlimb: effect of venous basic fibroblast growth factor retroinfusion. Endothelium 2003;10:257-265.

10 Heil M, Schaper W: Insights into pathways of arteriogenesis. Curr Pharm Biotechnol 2007; 8:35-42.

-11 Heil M, Ziegelhoeffer T, Pipp F, Kostin S, Martin S, Clauss M, Schaper W: Blood monocyte concentration is critical for enhancement of collateral artery growth. Am J Physiol Heart Circ Physiol 2002;283:H2411H2419.

$>12$ Eitenmuller I, Volger O, Kluge A, Troidl K, Barancik M, Cai WJ, Heil M, Pipp F, Fischer S, Horrevoets AJ, Schmitz-Rixen T, Schaper $\mathrm{W}$ : The range of adaptation by collateral vessels after femoral artery occlusion. Circ Res 2006;99:656-662.

-13 Rajanayagam MA, Shou M, Thirumurti V, Lazarous DF, Quyyumi AA, Goncalves L, Stiber J, Epstein SE, Unger EF: Intracoronary basic fibroblast growth factor enhances myocardial collateral perfusion in dogs. Am Coll Cardiol 2000;35:519-526.

14 van Royen N, Hoefer I, Buschmann I, Kostin S, Voskuil M, Bode C, Schaper W, Piek JJ: Effects of local MCP-1 protein therapy on the development of the collateral circulation and atherosclerosis in Watanabe hyperlipidemic rabbits. Cardiovasc Res 2003;57:178-185.

15 Pipp F, Boehm S, Cai WJ, Adili F, Ziegler B, Karanovic G, Ritter R, Balzer J, Scheler C, Schaper W, Schmitz-Rixen T: Elevated fluid shear stress enhances postocclusive collateral artery growth and gene expression in the pig hind limb. Arterioscler Thromb Vasc Biol 2004;24:1664-1668.

16 Longland CJ: The collateral circulation of the limb; Arris and Gale lecture delivered at the Royal College of Surgeons of England on 4th February, 1953. Ann R Coll Surg Engl 1953;13:161-176.
17 Dekker RJ, Boon RA, Rondaij MG, Kragt A, Volger OL, Elderkamp YW, Meijers JC, Voorberg J, Pannekoek H, Horrevoets AJ: Klf2 provokes a gene expression pattern that establishes functional quiescent differentiation of the endothelium. Blood 2006;107: 4354-4363.

18 Scholz D, Ziegelhoeffer T, Helisch A, Wagner S, Friedrich C, Podzuweit T, Schaper W: Contribution of arteriogenesis and angiogenesis to postocclusive hindlimb perfusion in mice. J Mol Cell Cardiol 2002;34:775787.

19 Schaper W, Scholz D: Factors regulating arteriogenesis. Arterioscler Thromb Vasc Biol 2003;23:1143-1151.

20 Hariawala MD, Horowitz JR, Esakof D, Sheriff DD, Walter DH, Keyt B, Isner JM, Symes JF: VEGF improves myocardial blood flow but produces EDRF-mediated hypotension in porcine hearts. J Surg Res 1996;63:77-82.

-21 Grundmann S, Hoefer I, Ulusans S, Bode C, Oesterle S, Tijssen JG, Piek JJ, Buschmann I, van Royen N: Granulocyte-macrophage colony-stimulating factor stimulates arteriogenesis in a pig model of peripheral artery disease using clinically applicable infusion pumps. J Vasc Surg 2006;43:1263-1269.

22 Heil M. Clauss M, Suzuki K, Buschmann IR, Willuweit A, Fischer S, Schaper W: Vascular endothelial growth factor (VEGF) stimulates monocyte migration through endothelial monolayers via increased integrin expression. Eur J Cell Biol 2000;79:850-857.

23 Vogel R, Zbinden R, Indermuhle A, Windecker S, Meier B, Seiler C: Collateral-flow measurements in humans by myocardial contrast echocardiography: validation of coronary pressure-derived collateral-flow assessment. Eur Heart J 2006;27:157-165.

24 Vogel S, Kubin T, von der Ahe D, Deindl E, Schaper W, Zimmermann R: Mek hyperphosphorylation coincides with cell cycle shut down of cultured smooth muscle cells. J Cell Physiol 2006;206:25-34. 
-25 Hong MK, Barry JJ, Leon MB: Multichannel balloon catheter. Semin Interv Cardiol 1996; 1:34-35.

-26 Schulick AH, Newman KD, Virmani R, Dichek DA: In vivo gene transfer into injured carotid arteries: optimization and evaluation of acute toxicity. Circulation 1995;91: 2407-2414.

-27 Palasis M, Luo Z, Barry JJ, Walsh K: Analysis of adenoviral transport mechanisms in the vessel wall and optimization of gene transfer using local delivery catheters. Hum Gene Ther 2000;11:237-246.

-28 Van Belle E, Maillard L, Rivard A, Fabre JE, Couffinhal T, Kearney M, Branellec D, Feldman LJ, Walsh K, Isner JM: Effects of poloxamer 407 on transfection time and percutaneous adenovirus-mediated gene transfer in native and stented vessels. Hum Gene Ther 1998;9:1013-1024.

-29 Shyu KG, Manor O, Magner M, Yancopoulos GD, Isner JM: Direct intramuscular injection of plasmid DNA encoding angiopoietin1 but not angiopoietin-2 augments revascularization in the rabbit ischemic hindlimb. Circulation 1998;98:2081-2087.

-30 Rissanen TT, Markkanen JE, Arve K, Rutanen J, Kettunen MI, Vajanto I, Jauhiainen S, Cashion L, Gruchala M, Narvanen O, Taipale P, Kauppinen RA, Rubanyi GM, YlaHerttuala S: Fibroblast growth factor 4 induces vascular permeability, angiogenesis and arteriogenesis in a rabbit hindlimb ischemia model. Faseb J 2003;17:100-102.

-31 Yamada N, Li W, Ihaya A, Kimura T, Morioka K, Uesaka T, Takamori A, Handa M, Tanabe S, Tanaka K: Platelet-derived endothelial cell growth factor gene therapy for limb ischemia. J Vasc Surg 2006;44:1322-1328.
32 Mittereder N, March KL, Trapnell BC: Evaluation of the concentration and bioactivity of adenovirus vectors for gene therapy. J Virol 1996;70:7498-7509.

33 Delli Bovi P, Basilico C: Isolation of a rearranged human transforming gene following transfection of kaposi sarcoma DNA. Proc Natl Acad Sci USA 1987;84:5660-5664.

34 Deindl E, Hoefer IE, Fernandez B, Barancik M, Heil M, Strniskova M, Schaper W: Involvement of the fibroblast growth factor system in adaptive and chemokine-induced arteriogenesis. Circ Res 2003;92:561-568.

35 Tzima E, Irani-Tehrani M, Kiosses WB, Dejana E, Schultz DA, Engelhardt B, Cao G, DeLisser H, Schwartz MA: A mechanosensory complex that mediates the endothelial cell response to fluid shear stress. Nature 2005. 437:426-431.

-36 Jin ZG, Ueba H, Tanimoto T, Lungu AO, Frame MD, Berk BC: Ligand-independent activation of vascular endothelial growth factor receptor 2 by fluid shear stress regulates activation of endothelial nitric oxide synthase. Circ Res 2003;93:354-363.

37 Kroll J, Waltenberger J: VEGF-a induces expression of eNOS and iNOS in endothelial cells via VEGF receptor-2 (kdr). Biochem Biophys Res Commun 1998;252:743-746.

38 Guzman RJ, Abe K, Zarins CK: Flow-induced arterial enlargement is inhibited by suppression of nitric oxide synthase activity in vivo. Surgery 1997;122:273-279; discussion 279-280.

39 Zacchigna S, Tasciotti E, Kusmic C, Arsic N, Sorace O, Marini C, Marzullo P, Pardini S, Petroni D, Pattarini L, Moimas S, Giacca M, Sambuceti G: In vivo imaging shows abnormal function of vascular endothelial growth factor-induced vasculature. Hum Gene Ther 2007; 18:515-524.
40 Grundmann S, PiekJJ, Pasterkamp G, Hoefer IE: Arteriogenesis: basic mechanisms and therapeutic stimulation. Eur J Clin Invest 2007;37:755-766

41 Hoefer IE, van Royen N, Buschmann IR, Piek JJ, Schaper W: Time course of arteriogenesis following femoral artery occlusion in the rabbit. Cardiovasc Res 2001;49:609-617.

42 Arras M, Ito WD, Scholz D, Winkler B, Schaper J, Schaper W: Monocyte activation in angiogenesis and collateral growth in the rabbit hindlimb. J Clin Invest 1998;101:4050.

43 Lu H, Xu X, Zhang M, Cao R, Brakenhielm E, Li C, Lin H, Yao G, Sun H, Qi L, Tang M, Dai H, Zhang Y, Su R, Bi Y, Zhang Y, Cao Y: Combinatorial protein therapy of angiogenic and arteriogenic factors remarkably improves collaterogenesis and cardiac function in pigs. Proc Nat Acad Sci USA 2007;104: 12140-12145

-44 Hirose K, Fujita M, Marui A, Arai Y, Sakaguchi H, Huang Y, Chandra S, Tabata Y, Komeda M: Combined treatment of sustained-release basic fibroblast growth factor and sarpogrelate enhances collateral blood flow effectively in rabbit hindlimb ischemia. Circ J 2006;70:1190-1194.

45 Cao R, Brakenhielm E, Pawliuk R, Wariaro D, Post MJ, Wahlberg E, Leboulch P, Cao Y: Angiogenic synergism, vascular stability and improvement of hind-limb ischemia by a combination of PDGF-bb and FGF-2. Nat Med 2003;9:604-613.

46 Chae JK, Kim I, Lim ST, Chung MJ, Kim WH, Kim HG, Ko JK, Koh GY: Coadministration of angiopoietin-1 and vascular endothelial growth factor enhances collateral vascularization. Arterioscler Thromb Vasc Biol 2000;20:2573-2578. 